\title{
A FACE OCULTA DA UNIVERSIDADE BRASILEIRA: PERCEPÇÕES DE COMPORTAMENTOS ILÍCITOS NA EDUCAÇÃO SUPERIOR POR ALUNOS E PROFESSORES
}

\author{
José Augusto Dela Coleta* \\ Luiz Roberto Gomes**
}

\begin{abstract}
RESUMO
Com o intuito de construir instrumentos de medida, e obter parâmetros de percepção de existência de condutas ilícitas emitidas por professores e alunos universitários, este artigo apresenta os resultados de um estudo realizado com 610 sujeitos, professores, coordenadores e alunos de diversos cursos de graduação. A coleta de dados foi realizada a partir de um instrumento em que se solicitava a porcentagem de emissão destes comportamentos pelos estudantes, e outro relativo às condutas dos professores. Os resultados mostram que os diversos comportamentos são percebidos como tendo altos níveis de frequência de ocorrência no meio universitário, tanto por coordenadores, professores e alunos, com diferenças significativas entre esses três grupos de sujeitos, bem como ao se considerar as diferentes IES participantes deste estudo.
\end{abstract}

Palavras-chave: Educação superior. Comportamentos acadêmicos e pedagógicos ilícitos. Formação acadêmica.

\begin{abstract}
In order to build measuring instruments, and obtain the parameters of perception of the existence of illegal conduct issued by teachers and university students, this article presents the results of a study of 610 subjects, teachers, engineers and students from various undergraduate
\end{abstract}

\footnotetext{
* Doutorado em Psicologia Social pela Fundação Getúlio Vargas (FGV-RJ). Professor aposentado pela Universidade Federal de Uberlândia (UFU).E-mail: dela.coleta@netsite. com.br

** Doutorado em Educação pela Universidade Estadual de Campinas (UNICAMP). Professor permanente do Programa de Pós-Graduação em Educação da Universidade Federal de São Carlos (UFSCAR).E-mail: luizroberto.gomes@gmail.com
} 
courses. Data collection was performed from an instrument which called on the percentage of emission of these behaviors by students, and another concerning the conduct of teachers. The results show that the different behaviors are perceived as having high levels of frequency in academia by coordinators, teachers and students, with significant differences among these three groups of subjects, as well as when considering the different IES study participants.

Keywords: Higher education. Academic and pedagogic illicit behavior. Academic education.

\section{Introdução}

A Educação, enquanto Paidéia, no sentido grego da formação integral do Homem; e Bildung, na acepção alemã da formação cultural, encontra-se muitas vezes eclipsada quando são analisados os processos acadêmicos e pedagógicos que constituem a formação universitária. Tratase de investigar o que de fato ocorre nas Instituições de Educação Superior (IES), com o propósito de identificar, com maior clareza, as relações que nutrem o processo de ensino e aprendizagem.

A premissa de trabalho adotada neste estudo supõe que a face oculta da educação, ao não revelar os procedimentos e concepções que orientam as práticas acadêmicas e pedagógicas, incorre em danos, não só para a aprendizagem, mas também para a cultura organizacional das IES e da formação acadêmica como um todo, comprometendo, portanto, o desenvolvimento científico e cultural da sociedade contemporânea. Ao invés de promover a cultura e a emancipação, a educação superior acaba por conduzir a sociedade cada vez mais à alienação e à barbárie ${ }^{1}$.

Essa dimensão oculta da realidade já fora abordada por Platão (1993) no Livro VII da República, também conhecido por Alegoria da Caverna, por Horkheimer (2000) no Eclipse da Razão, por Adorno e

1 Conferir a análise, acerca do processo de instrumentalização da cultura e da educação, desenvolvida pelo filósofo francês Jean-François Mattei em seu livro A barbárie interior: ensaio sobre o i-mundo moderno. São Paulo: UNESP, 2002. 
Horkheimer (1985) na Dialética do Esclarecimento, por Habermas (1999) na Teoria da Ação Comunicativa e, mais recentemente, por Levitt e Dubner (2005) no Freakonomics, por Gomes (2006) em A Indústria Cultural Hoje e Gomes (2007) em Educação e Consenso em Habermas.

No Eclipse da Razão de 1946, Max Horkheimer salienta os efeitos de uma razão eclipsada em sua face instrumental, em que "o conhecimento técnico expande o horizonte da atividade e do pensamento humano, a autonomia do homem enquanto indivíduo e a sua capacidade de opor resistência ao crescente mecanismo de manipulação das massas" (HORKHEIMER, 2000, p. 9).

Na Theorie der Halbbildung (Teoria da Semicultura), Adorno (1996) faz uma análise da crise da formação cultural na contemporaneidade, identificando que esta não é um simples objeto da pedagogia, e sim, da semiformação que passou a ser a forma dominante da consciência atual:

O que hoje se manifesta como crise da formação cultural ${ }^{2}$ não é um simples objeto da pedagogia, que teria que se ocupar diretamente desse fato, mas também não pode se restringir a uma sociologia que apenas justaponha conhecimentos a respeito da formação (...) Reformas pedagógicas isoladas, embora indispensáveis, não trazem contribuições substanciais. Poderiam até, em certas ocasiões, reforçar a crise, porque abrandam as necessárias exigências a serem feitas aos que devem ser educados e porque revelam uma inocente despreocupação diante do poder que a realidade exerce sobre eles (...) A formação cultural agora se converte em uma semiformação socializada, na onipresença do espírito alienado, que, segundo sua gênese e seu sentido, não antecede à formação cultural, mas a sucede (ADORNO, 1996, p. 388).

O conceito de semiformação sugere uma reflexão mais aprofundada das condições e dos processos de ensino e aprendizagem que caracterizam a formação cultural e, mais especificamente, a formação acadêmica. É pela face eclipsada do fenômeno, que aspectos diferenciados da correlação de causalidade acadêmico-pedagógica poderão emergir, de modo a esclarecer

2 Theodor W. Adorno. Theorie der Halbbildung. Frankfurt; Suhhrkamp Verlang, am Main 1972 (Sociologische Schriften I), p. 93-121. 
o que de fato tem orientado os comportamentos que estabelecem a formação acadêmica hoje.

Levitt e Dubner, ao procederem à análise sobre o lado oculto de tudo, identificaram algumas categorias que poderão alterar a percepção da sabedoria convencional sobre os fenômenos emergentes da sociedade contemporânea:

- Apenas porque duas coisas são correlatas isso não significa que uma delas tenha como conseqüência a outra;

- Os incentivos são a pedra de toque da vida moderna;

- A sabedoria convencional em geral está equivocada;

- Causas distintas e até mesmo sutis podem, muitas vezes, provocar efeitos drásticos;

- Saber o que medir e como medir faz o mundo parecer muito complicado (LEVITT; DUBNER, 2005, p. 12-16).

Essas categorias enunciadas por Levitt e Dubner (2005) apresentam outra perspectiva de análise para os estudos dos fenômenos sociais, principalmente, quando se leva em consideração o lado oculto das coisas. Tal como em Adorno e Horkheimer (1985), os paradoxos da sociedade contemporânea indicam que: "no sentido mais amplo do progresso do pensamento, o esclarecimento tem perseguido sempre o objetivo de livrar os homens do medo e de investi-los na posição de senhores. Mas a terra totalmente esclarecida resplandece sob o signo de uma calamidade triunfal" (ADORNO \& HORKHEIMER, 1985, p. 19).

Especificamente, no contexto acadêmico e pedagógico, muitas são as situações eclipsadas, e estas além de não revelarem a verdadeira face da realidade educacional, acabam corrompendo o verdadeiro sentido da educação. A esse respeito, é importante salientar o alerta de Adorno em Educação e Emancipação (1995), de que a educação não é necessariamente um fator de emancipação: "É necessário contrapor-se a tal ausência de consciência, é preciso evitar que as pessoas golpeiem para os lados sem refletir a respeito de si próprias. A educação tem sentido unicamente como educação dirigida a uma auto-reflexão crítica" (ADORNO, 1995, p. 121).

No bojo da análise sobre o lado oculto das coisas, os estudos empreendidos por Levitt e Dubner esclarecem, por intermédio do conceito 
de trapaça $^{3}$, que existe um incentivo econômico, social e moral que conduz as pessoas a cometerem atos ilícitos. "Trapacear pode ou não ser uma característica da natureza humana, mas sem dúvida tem participação crucial em praticamente todas as empreitadas do homem" (LEVITT; DUBNER, 2005, p. 27). No aspecto econômico, a trapaça significa obter mais gastando menos, no social, a busca da promoção social a qualquer preço, no aspecto moral, trata-se do efeito à integridade moral das pessoas.

É com base no conceito e nos incentivos à trapaça que se justifica a pertinência da inserção dessa categoria de análise para o entendimento da face oculta da educação.

O jornal Folha de São Paulo, em sua edição de 11 de novembro de 2007, a página $\mathrm{C} 1$, traz a informação que, amparados por nada menos que 19 dispositivos legais, 30.000 professores faltam por dia nas escolas da rede pública do Estado de São Paulo, correspondentes a 12.8\% do total de docentes em atividades, enquanto na rede particular o índice de faltas é inferior a $1 \%$ naquele Estado, dados que serviram de sustentação à proposta de políticas públicas estimuladoras de frequência dos professores ao trabalho.

Levitt e Dubner relatam um estudo com um conjunto de dados de escolas de Chicago, nos Estados Unidos, que revela a existência de trapaças de professores e alunos em mais de duas mil turmas por ano, aproximadamente $5 \%$ do total. Os dados relevam ainda que:

Em estudo recente feito com professores da Carolina do Norte, cerca de $35 \%$ dos entrevistados responderam já ter visto seus colegas trapacearem (...) Os dados de Chicago mostram que homens e mulheres são igualmente propensos a trapacear. Um professor trapaceiro em geral é mais moço e menos qualificado do que a média. Por outro lado, o risco de que trapaceie aumenta quando há mudança em seus incentivos (...) Os professores nas turmas de pior desempenho apresentaram maior tendência para trapacear (LEVITT; DUBNER, 2005, p. 36-37).

\footnotetext{
3 Segundo o Dicionário Houaiss da Língua Portuguesa (2004), o verbete trapaça pode significar: contrato fraudulento feito com quem empresta dinheiro, qualquer ação ardilosa, de má-fé. A acepção da palavra que estará sendo utilizada nesse estudo é a de ação ardilosa e de má-fé.
} 
Os estudos desenvolvidos por Levitt e Dubner (2005) motivam a necessidade de outras análises acerca do problema dos atos ilícitos no processo acadêmico e pedagógico, em especial, na educação superior, uma vez que no Brasil, há fortes indícios de natureza econômica, social e moral, para que esse fenômeno também ocorra de forma significativa nas IES.

Masetto ao se referir sobre a aula na educação superior como um ambiente de aprendizagem e de trabalho profissional do docente, enfatiza que:

A relação entre os participantes do processo de aprendizagem (professores e alunos) torna-se uma ação em equipe, voltada para a consecução dos objetivos educacionais propostos. Uma relação que desenvolva entre professores e alunos a co-responsabilidade pelo aprendizado, a parceria, um relacionamento de diálogo e respeito entre pessoas adultas. Um relacionamento que permita a professores e alunos trazerem suas experiências, vivências, conhecimentos, interesses e problemas, bem como análises das questões para serem interpretadas e discutidas (MASETTO, 2003, p. 73-74).

Como bem demonstrou Massetto (2003), o processo de ensinoaprendizagem pressupõe a definição clara de objetivos, uma relação de coresponsabilidade entre alunos e professores e, sobretudo, uma ação pedagógica que conduza à aprendizagem. Habermas atribui essa coresponsabilidade à competência comunicativa dos participantes do discurso que, necessariamente, precisam pressupor algumas condições para que haja a busca cooperativa da verdade:

Todo agente que atue comunicativamente tem que assegurar, na execução do agir, pretensões universais de validade e supor que tais pretensões podem desempenhar-se. Na medida em que queira participar em um processo de entendimento, não pode deixar de assegurar as seguintes pretensões universais de validade: a de estar se expressando inteligivelmente, a de estar dando a entender algo, a de estar permitindo-se a entender, e a de entender-se com os demais (HABERMAS, 2001, p. 300). 
As análises empreendidas por Habermas (1983; 1999), ao enfatizar as exigências de regras e de pretensões de validade para a legitimação do agir comunicativo, corroboram a necessidade de estudos que explicitem e façam a crítica às ações fraudulentas supostamente contidas no processo pedagógico e acadêmico das IES. Por hipótese, a desconsideração de tais pressuposições de validade poderá conduzir o processo pedagógico à semiformação, no sentido de Adorno (1996), e à incidência de trapaças, no sentido de Levitt e Dubner (2005).

Para Habermas (2001), o agir comunicativo, diferentemente da ação estratégica, possui elementos formativos capazes de promover consensos ${ }^{4}$, sobretudo por exigir dos participantes de um discurso: "a capacidade de distinguir fielmente entre ser e aparência, essência e fenômeno, ser e dever, para poder julgar competentemente acerca da verdade dos enunciados, a veracidade das emissões e a retidão das ações" (HABERMAS, 2001, p. 104). Por analogia, a ação educativa, quando prescinde da finalidade maior que é a formação de um ser humano íntegro e reto, induz a ação pedagógica à cultura da trapaça, e por isso, acaba por comprometer todo o processo educacional.

Com tais reflexões introdutórias, o presente trabalho teve por objetivos identificar situações de trapaças possivelmente existentes em IES, envolvendo atividades pedagógicas e acadêmicas no processo de ensino-aprendizagem, perpetradas por professores ou alunos; construir escalas para medir a percepção de coordenadores, professores e alunos sobre a frequência com que estes fenômenos ocorrem em diferentes IES; determinar parâmetros de ocorrência destes fenômenos em algumas IES; identificar critérios objetivos que possam demonstrar a ocorrência de fatos relacionados a condutas ilícitas no processo de ensino-aprendizagem e discutir as implicações que a presença de fenômenos desta natureza possam acarretar à formação superior.

4 GOMES, Luiz Roberto. Educação e Consenso em Habermas. Campinas: Alínea, 2007. 


\section{Metodologia}

\subsection{Participantes}

Tomaram parte neste estudo 610 sujeitos, sendo 463 estudantes dos últimos períodos de diversos cursos de graduação (Administração, Direito, Engenharia, Fisioterapia e Psicologia), 73 professores de diferentes especialidades, de quatro IES particulares e duas públicas das cidades de Uberlândia, Anápolis e Uruaçu, do interior dos estados de Goiás e Minas Gerais, um grupo de 22 coordenadores de cursos de graduação de uma IES particular, e ainda 52 professores e alunos de cursos superiores mantidos por uma Escola Agrotécnica Federal (EAF), ambas do interior do Estado de Minas Gerais.

\subsection{Instrumentos}

Para a coleta de dados foi concebido um conjunto de dez itens relativos à percepção da porcentagem de emissão de comportamentos de trapaça por parte dos estudantes universitários e de outros dezoito itens relativos a condutas ilícitas de professores da educação superior. Para identificação dos comportamentos envolvendo trapaças, por parte dos estudantes e professores, incluídos nos instrumentos utilizados para a obtenção de dados, foram organizados dois grupos focais, um constituído por 13 professores e outro por 21 alunos. Eles foram solicitados a indicar todas as situações, das quais se lembrassem, em que houvesse condutas fraudulentas da parte dos docentes ou discentes.

Os itens componentes da escala relativa a situações de trapaça perpetradas pelos estudantes envolviam:

1) Presença nas aulas, apenas nos momentos próximos à chamada;

2) Presença apenas nas aulas em que os professores fazem chamada;

3) Responder chamada em nome de outros colegas faltosos;

4) Fotocopiar cadernos, resumos e anotações elaborados pelos colegas;

5) Realização de outras atividades alheias ao assunto da disciplina, durante as aulas; 
6) Adoção de estratégias de divisão na elaboração dos trabalhos entre membros dos grupos nas diversas disciplinas;

7) Cópia (da internet) de trabalhos prontos para entregar aos professores;

8) Solicitação, ou pagamento a outras pessoas para fazer os trabalhos escolares solicitados;

9) Colar na prova em pelo menos uma disciplina e

10) Colar na prova em pelo menos metade das disciplinas.

A escala para medida dos níveis percebidos de presença de situações de trapaça envolvendo comportamentos pedagógicos dos docentes incluía dezoito itens:

1) Chegar pelo menos 10 minutos depois do horário marcado para o inicio das aulas;

2) Terminar as aulas pelo menos 10 minutos mais cedo do que o horário previsto;

3) Dar aulas "sem conteúdos", superficiais, que comprometem a aprendizagem efetiva da matéria;

4) Leitura ou solicitação aos alunos para que façam a leitura, em sala de aula, dos textos indicados para serem lidos em casa;

5) Preenchimento de grande parte do período destinado às aulas com narrativas de casos pessoais, piadas, ou conteúdos alheios à matéria;

6) Definição do conteúdo do programa da disciplina em função da opinião e preferência dos alunos;

7) Solicitação aos alunos para apresentarem seminários, em substituição às aulas que ele deveria ministrar;

8) Favorecimento, na nota, dos alunos mais próximos, mais conhecidos;

9) Aplicação de provas a serem respondidas em duplas, trios ou grupos maiores;

10) Utilização de autoavaliação dos alunos como critério para atribuição de notas; 
11) Aplicação de provas ou trabalhos compensatórios (derecuperação), aos alunos que foram mal em suas provas;

12) Atribuição de notas aos alunos pelo nível de participação nas aulas;

13) Avaliação, com maior rigor, dos alunos que costumam apresentar melhor desempenho;

14) Condutas menos rigorosas na avaliação, com os alunos que vão mal nas provas;

15) Aplicação de provas que os alunos devem responder em casa;

16) Informar anteriormente aos alunos as questões da prova;

17) Aplicação da mesma prova utilizada em semestres anteriores e

18) Determinação do nível de dificuldade da prova em função da opinião dos alunos sobre a quantidade do conteúdo aprendido.

As respostas dos sujeitos expressavam escores intervalares que se referiam à porcentagem percebida, entre 11 opções, variando de 1 a 99 , de professores ou alunos que emitiam cada um dos comportamentos na instituição em que o sujeito estudava ou trabalhava.

Além das duas escalas para medida dos níveis de presença percebida de comportamentos de trapaça por parte de estudantes e professores, uma outra variável foi incluída no estudo. Trata-se das notas obtidas por 1.276 estudantes de uma das instituições particulares, pertencentes a uma das vinte disciplinas, de 40 turmas diferentes, dos mais variados cursos de graduação, ambas escolhidas ao acaso. As notas referiam-se ao primeiro e segundo bimestres, do primeiro e segundo semestres do mesmo ano letivo, e foram obtidas por meio da consulta ao mapa de notas de cada uma das disciplinas, em suas respectivas turmas.

\subsection{Procedimentos}

Os estudantes, que pertenciam a turmas de cursos de graduação escolhidas ao acaso, foram abordados em sala de aula e solicitados a responder livremente os diferentes itens do instrumento, indicando as porcentagens de alunos e professores de sua instituição que emitiriam cada um dos comportamentos apresentados. Os professores e coordenadores, 
escolhidos ao acaso, receberam o mesmo instrumento e deveriam, tanto quanto os estudantes, indicar que porcentagem de estudantes ou professores emitiam aqueles comportamentos em sua IES.

No que diz respeito às notas dos alunos nas disciplinas, nos dois bimestres, dos dois semestres considerados, tendo em vista que os totais de pontos máximos em cada bimestre são diferentes, houve necessidade de transformá-las em uma única base de 100 pontos máximos cada.

Os dados foram codificados e processados eletronicamente por meio do Statistical Package for the Social Sciences (SPSS), versão 11.0.

\subsection{Resultados}

Os tratamentos estatísticos impostos aos dados coletados visaram, em primeiro lugar, verificar as qualidades métricas das duas escalas propostas. Os resultados mostram que os escores nos dez itens da escala para medida das porcentagens percebidas de presença de comportamentos acadêmicos ilícitos perpetrados por estudantes apresentam correlações positivas, altas e significativas com o escore total da escala, variando entre 0,47 e 0,76 , com coeficiente alfa de Cronbach igual a 0,89 .

No que tange à escala para medida das porcentagens percebidas de presença de comportamentos pedagógicos ilícitos emitidos pelos professores, as correlações entre os escores obtidos em cada um dos dezoito itens, e no total da escala variaram de 0,40 a 0,60 , com o coeficiente alfa de Cronbach igual a 0,87 .

Uma análise fatorial confirmatória, utilizando o método dos componentes principais indicou, no caso da escala destinada a medir a frequência de comportamentos de trapaças emitidos pelos estudantes, que o fator principal explica $43,30 \%$ da variância comum dos resultados, com a carga fatorial variando entre 0,52 e 0,78 nos dez itens componentes da escala. No caso da escala destinada a mensurar a frequência de emissões de comportamentos de trapaças pelos professores, o mesmo tratamento indicou que o fator principal responde por 32,93\% da variância comum dos dados, com a carga fatorial dos dezoito itens, no fator principal, variando entre 0,32 e 0,72 . 
Estudando-se as respostas dos 536 sujeitos, professores e alunos de IES públicas e particulares, independentemente do grupo a que pertencem, verificaram-se diferenças importantes nas porcentagens percebidas de presença dos diferentes comportamentos acadêmicos ilícitos emitidos pelos alunos. Os dados mostram que os sujeitos deste estudo, professores e alunos, percebem que mais de $40 \%$ dos estudantes de sua IES adotam condutas associadas a colar na prova em pelo menos uma disciplina, fotocopiar cadernos dos colegas, presenças nas aulas apenas nos momentos próximos à chamada, colar nas provas em metade das disciplinas, dividir a realização de trabalhos acadêmicos, presença apenas nas aulas em que os professores fazem chamada, tal como demonstrado na TAB. 1 .

\section{TABELA 1}

Médias e desvios-padrão dos níveis de presença percebida (entre 1 e 99), por professores e alunos, dos dez comportamentos acadêmicos ilícitos emitidos por estudantes $(\mathrm{N}=536)$

\begin{tabular}{|l|c|c|}
\hline \multicolumn{1}{|c|}{ Itens } & Médias & Desvios-padrão \\
\hline 1. Estão presentes na aula apenas no momento da chamada & 44,08 & 29,46 \\
\hline $\begin{array}{l}\text { 2. Presentes apenas nas aulas em que os professores fazem } \\
\text { chamadas }\end{array}$ & 42,26 & 29,71 \\
\hline 3. Respondem a chamada para os colegas faltosos & 14,71 & 20,31 \\
\hline 4. Fotocopiam cadernos & 47,50 & 30,03 \\
\hline 5. Fazem atividades alheias ao assunto da aula & 39,56 & 25,88 \\
\hline 6. Dividem a realização dos trabalhos acadêmicos & 43,56 & 29,52 \\
\hline 7. Baixam trabalhos da internet & 37,18 & 28,28 \\
\hline 8. Pagam a outros a realização dos trabalhos acadêmicos & 25,47 & 23,08 \\
\hline 9. Colam na prova em pelo menos uma disciplina & 51,37 & 32,38 \\
\hline 10. Colam nas provas em metade das disciplinas & 41,09 & 29,76 \\
\hline
\end{tabular}

As respostas destes mesmos 536 sujeitos, aos itens denotando a presença de comportamentos pedagógicos ilícitos emitidos por docentes, indicam maiores índices de presença de condutas associadas a terminar as aulas dez minutos mais cedo, solicitar aos alunos que façam seminários em substituição às suas aulas, chegar dez minutos depois da hora prevista para a aula, atribuir notas pela participação dos alunos, ministrar aulas "sem conteúdo", ler ou pedir aos alunos que leiam textos em aula, avaliar 
com maior rigor alunos que apresentam desempenho superior, determinar o nível de dificuldade das provas a partir da opinião dos alunos e aplicar as mesmas provas que em semestres anteriores. Como se pode observar na TAB. 2, estes comportamentos ilícitos são percebidos como sendo emitidos por mais de $20 \%$ dos professores das IES às quais os sujeitos estão vinculados.

\section{TABELA 2}

Médias e desvios-padrão dos níveis de presença percebida (entre 1 e 99), por professores e alunos, dos diversos comportamentos pedagógicos ilícitos emitidos por professores $(\mathrm{N}=536)$

\begin{tabular}{|l|c|c|}
\hline \multicolumn{1}{|c|}{ Itens } & Médias & Desvios-padrão \\
\hline $\begin{array}{l}\text { 1. Chegam dez minutos depois da hora prevista para o início } \\
\text { da aula }\end{array}$ & 30,82 & 30,48 \\
\hline 2. Terminam a aula dez minutos mais cedo & 41,27 & 32,38 \\
\hline 3. Dão aulas "sem conteúdos" & 26,94 & 26,55 \\
\hline $\begin{array}{l}\text { 4. Lêem ou pedem aos alunos que façam a leitura, em sala } \\
\text { de aula, dos textos }\end{array}$ & 26,26 & 26,28 \\
\hline $\begin{array}{l}\text { 5. Preenchem grande parte da aula com narrativas de casos } \\
\text { pessoais }\end{array}$ & 17,77 & 20,80 \\
\hline $\begin{array}{l}\text { 6. Definem o conteúdo do programa da disciplina em função } \\
\text { da opinião dos alunos }\end{array}$ & 20,23 & 22,16 \\
\hline $\begin{array}{l}\text { 7. Solicitam aos alunos que façam seminários em substitui- } \\
\text { ção às aulas }\end{array}$ & 34,10 & 29,02 \\
\hline 8. Favorecem, na nota, os alunos mais próximos. & 19,02 & 25,05 \\
\hline 9. Aplicam provas em duplas & 15,49 & 19,53 \\
\hline $\begin{array}{l}\text { 10. Utilizam auto-avaliação dos alunos como critério para } \\
\text { atribuição de notas }\end{array}$ & 14,20 & 20,75 \\
\hline $\begin{array}{l}\text { 11. Dão provas compensatórias aos alunos que foram mal na } \\
\text { prova }\end{array}$ & 15,81 & 20,88 \\
\hline 12. Atribuem notas pela participação dos alunos & 27,10 & 24,16 \\
\hline $\begin{array}{l}\text { 13. Avaliam com maior rigor os alunos que apresentam } \\
\text { melhor desempenho }\end{array}$ & 24,96 & 27,46 \\
\hline 14. São menos rigorosos com alunos que vão mal nas provas & 14,84 & 19,26 \\
\hline 15. Aplicam provas que os alunos devem responder em casa & 6,84 & 12,85 \\
\hline 16. Informam anteriormente aos alunos as questões de prova & 7,70 & 14,88 \\
\hline 17. Aplicam a mesma prova de semestres anteriores & 20,56 & 24,27 \\
\hline $\begin{array}{l}\text { 18. Definem o conteúdo da prova em função da opinião dos } \\
\text { alunos }\end{array}$ & 21,00 & 22,91 \\
\hline
\end{tabular}


Ao se considerar a soma dos escores obtidos pelos sujeitos dos onze grupos distintos (quatro grupos de professores de quatro IES diferentes, um grupo de coordenadores de cursos, quatro grupos de alunos de quatro IES diferentes, um grupo de professores e um grupo de estudantes de uma EAF), retratando a emissão dos dez comportamentos acadêmicos ilícitos emitidos por estudantes por um lado, e das dezoito condutas emitidas por docentes por outro, observam-se diferenças estatisticamente significativas entre os grupos quanto à percepção das porcentagens dos níveis de presença destes comportamentos dos estudantes (F (10,609) 2,59 p<01) ou dos docentes $(\mathrm{F}(10,609)=4,20 \mathrm{p}<001)$, o mesmo ocorrendo quando se consideram somente três grupos diferentes de sujeitos compostos por coordenadores, professores e alunos, de todas as IES e EAF.

Considerando-se as diferenças nos escores obtidos por estudantes e professores de IES públicas ou particulares (TAB. 3) relativos aos comportamentos ilícitos emitidos por alunos, observam-se diferenças estatisticamente significativas em três das dez categorias, com os sujeitos das IES públicas percebendo maiores frequências destas condutas do que aqueles vinculados às IES particulares. Variação na mesma direção, porém sem significância estatística, pode ser observada quando se considera o total dos escores indicativos da frequência de emissão destes comportamentos ilícitos, percebidos como mais frequentes nas IES públicas do que nas IES particulares. 


\section{TABELA 3}

Médias, desvios-padrão e teste das diferenças entre as médias dos escores indicativos da frequência de emissão de comportamentos de trapaça pelos estudantes universitários, de sujeitos professores e alunos de IES públicas e particulares

\begin{tabular}{|c|c|c|c|c|c|}
\hline \multirow{2}{*}{ Itens } & \multicolumn{2}{|c|}{$\begin{array}{c}\text { IES Públicas } \\
\text { (N 136) }\end{array}$} & \multicolumn{2}{|c|}{$\begin{array}{l}\text { IES Particulares } \\
(\mathrm{N} 400)\end{array}$} & \multirow{2}{*}{$\mathbf{t}$} \\
\hline & Médias & $\begin{array}{c}\text { Desvios- } \\
\text { padrão }\end{array}$ & Médias & $\begin{array}{l}\text { Desvios- } \\
\text {-padrão }\end{array}$ & \\
\hline $\begin{array}{l}\text { 1. Presença nas aulas, apenas } \\
\text { nos momentos próximos à cha- } \\
\text { mada; }\end{array}$ & 43,98 & 27,16 & 44,12 & 30,23 & $-0,05$ \\
\hline $\begin{array}{l}\text { 2. Presença apenas nas aulas em } \\
\text { que os professores fazem cha- } \\
\text { mada; }\end{array}$ & 47,02 & 28,18 & 40,64 & 30,08 & $2,24 *$ \\
\hline $\begin{array}{l}\text { 3. Responder chamada em nome } \\
\text { de outros colegas faltosos; }\end{array}$ & 15,84 & 20,01 & 14,33 & 20,42 & 0,75 \\
\hline $\begin{array}{l}\text { 4. Fotocopiar cadernos, resu- } \\
\text { mos e anotações elaborados pe- } \\
\text { los colegas; }\end{array}$ & 45,98 & 27,70 & 48,02 & 30,79 & $-0,72$ \\
\hline $\begin{array}{l}\text { 5. Realização de outras ativida- } \\
\text { des alheias ao assunto da disci- } \\
\text { plina, durante as aulas; }\end{array}$ & 39,92 & 22,09 & 39,44 & 27,07 & 0,21 \\
\hline $\begin{array}{l}\text { 6. Adoção de estratégias de di- } \\
\text { visão dos trabalhos em grupo } \\
\text { nas diversas disciplinas; }\end{array}$ & 51,43 & 29,49 & 40,88 & 29,09 & $3,61 * *$ \\
\hline $\begin{array}{l}\text { 7. Cópia de trabalhos prontos } \\
\text { da internet para entregar aos } \\
\text { professores; }\end{array}$ & 36,92 & 25,32 & 37,27 & 29,25 & $-0,13$ \\
\hline $\begin{array}{l}\text { 8. Solicitação, ou pagamento } \\
\text { a outras pessoas para fazer os } \\
\text { trabalhos escolares solicitados } \\
\text { pelos professores; }\end{array}$ & 26,49 & 21,84 & 25,12 & 23,50 & 0,62 \\
\hline $\begin{array}{l}\text { 9. Colar na prova em pelo me- } \\
\text { nos uma disciplina; }\end{array}$ & 56,15 & 28,94 & 49,74 & 33,34 & $2,14 *$ \\
\hline $\begin{array}{l}\text { 10. Colar na prova em pelo me- } \\
\text { nos metade das disciplinas. }\end{array}$ & 39,10 & 24,95 & 41,77 & 31,22 & $-1,01$ \\
\hline Total & 402,82 & 159,54 & 381,41 & 203,45 & 1,25 \\
\hline
\end{tabular}

$* \mathrm{p}<05$

$* * \mathrm{p}<01$ 
O mesmo fenômeno pode ser observado quando se comparam as médias dos escores indicativos da frequência de comportamentos ilícitos emitidos pelos docentes com os sujeitos das IES públicas, percebendo maiores frequências destas condutas do que os sujeitos das IES particulares, sendo que em doze dos dezoito comportamentos, e no total deles, estas diferenças atingem níveis importantes de significância estatística (TAB. 4).

\section{TABELA 4}

Médias, desvios-padrão e teste das diferenças entre as médias dos escores indicativos da frequência de emissão de comportamentos de trapaça pelos professores universitários, de sujeitos professores e alunos de IES públicas e particulares

\begin{tabular}{|c|c|c|c|c|c|}
\hline \multirow{2}{*}{ Itens } & \multicolumn{2}{|c|}{$\begin{array}{l}\text { IES Públicas } \\
\text { (N 136) }\end{array}$} & \multicolumn{2}{|c|}{$\begin{array}{l}\text { IES Particulares } \\
\text { (N 400) }\end{array}$} & \multirow{2}{*}{$\mathbf{t}$} \\
\hline & Médias & $\begin{array}{l}\text { Desvios- } \\
\text { padrão }\end{array}$ & Médias & $\begin{array}{c}\text { Desvios- } \\
\text { padrão }\end{array}$ & \\
\hline $\begin{array}{l}\text { 1. Chegam dez minutos depois da } \\
\text { hora prevista para o início da aula }\end{array}$ & 45,34 & 29,87 & 25,87 & 29,10 & $6,69 * *$ \\
\hline $\begin{array}{l}\text { 2. Terminam a aula dez minutos } \\
\text { mais cedo }\end{array}$ & 58,37 & 27,77 & 35,45 & 31,81 & $8,00 * *$ \\
\hline 3. Dão aulas "sem conteúdos" & 39,70 & 23,97 & 22,64 & 26,02 & $6,99 * *$ \\
\hline $\begin{array}{l}\text { 4. Lêem ou pedem aos alunos que } \\
\text { façam a leitura, em sala de aula, } \\
\text { dos textos }\end{array}$ & 30,95 & 23,77 & 24,66 & 23,93 & $2,57 * *$ \\
\hline $\begin{array}{l}\text { 5. Preenchem grande parte da } \\
\text { aula com narrativas de casos pes- } \\
\text { soais }\end{array}$ & 25,47 & 21,43 & 15,17 & 20,02 & $5,08 * *$ \\
\hline $\begin{array}{l}\text { 6. Definem o conteúdo do pro- } \\
\text { grama da disciplina em função da } \\
\text { opinião dos alunos }\end{array}$ & 24,45 & 22,52 & 18,79 & 21,88 & $2,58 * *$ \\
\hline $\begin{array}{l}\text { 7. Solicitam aos alunos que fa- } \\
\text { çam seminários em substituição } \\
\text { às aulas }\end{array}$ & 43,60 & 29,38 & 30,87 & 28,21 & $4,50 * *$ \\
\hline $\begin{array}{l}\text { 8. Favorecem, na nota, os alunos } \\
\text { mais próximos. }\end{array}$ & 22,55 & 24,66 & 17,81 & 25,10 & $1,93^{*}$ \\
\hline 9. Aplicam provas em duplas & 24,51 & 22,04 & 12,43 & 17,61 & $6,46^{* *}$ \\
\hline $\begin{array}{l}\text { 10. Utilizam auto-avaliação dos } \\
\text { alunos como critério para atribui- } \\
\text { ção de notas }\end{array}$ & 15,11 & 19,44 & 13,89 & 21,19 & 0,62 \\
\hline
\end{tabular}




\begin{tabular}{|c|c|c|c|c|c|}
\hline $\begin{array}{l}\text { 11. Dão provas compensatórias } \\
\text { aos alunos que foram mal na pro- } \\
\text { va }\end{array}$ & 19,97 & 19,92 & 14,39 & 21,03 & $2,78 * *$ \\
\hline $\begin{array}{l}\text { 12. Atribuem notas pela partici- } \\
\text { pação dos alunos }\end{array}$ & 27,92 & 21,79 & 26,83 & 24,93 & 0,49 \\
\hline $\begin{array}{l}\text { 13. Avaliam com maior rigor os } \\
\text { alunos que apresentam melhor } \\
\text { desempenho }\end{array}$ & 25,74 & 26,66 & 24,69 & 27,76 & 0,39 \\
\hline $\begin{array}{l}\text { 14. São menos rigorosos com } \\
\text { alunos que vão mal nas provas }\end{array}$ & 18,35 & 18,92 & 13,64 & 19,25 & $2,49 *$ \\
\hline $\begin{array}{l}\text { 15. Aplicam provas que os alunos } \\
\text { devem responder em casa }\end{array}$ & 11,69 & 15,46 & 5,24 & 11,39 & $5,18 * *$ \\
\hline $\begin{array}{l}\text { 16. Informam anteriormente aos } \\
\text { alunos as questões de prova }\end{array}$ & 7,59 & 12,46 & 7,74 & 15,64 & $-0,11$ \\
\hline $\begin{array}{l}\text { 17. Aplicam a mesma prova de } \\
\text { semestres anteriores }\end{array}$ & 21,54 & 24,28 & 20,23 & 24,29 & 0,54 \\
\hline $\begin{array}{l}\text { 18. Definem o conteúdo da prova } \\
\text { em função da opinião dos alunos }\end{array}$ & 23,19 & 22,95 & 20,25 & 22,88 & 1,23 \\
\hline Total & 482,46 & 229,90 & 352,78 & 234,32 & $5,54 * *$ \\
\hline
\end{tabular}

Quando se compararam os escores obtidos por professores e alunos, verifica-se que os estudantes tendem a perceber frequências maiores de emissão de comportamentos ilícitos, por parte dos alunos, do que o fazem os professores (TAB. 5), ocorrendo o inverso ao se considerar as condutas ilícitas perpetradas pelos professores, quando os docentes percebem maiores índices de ocorrência destes comportamentos entre os professores do que o fazem os estudantes (TAB. 6). 


\section{TABELA 5}

Médias, desvios-padrão e teste das diferenças entre as médias dos escores indicativos da frequência de emissão de comportamentos de trapaça pelos estudantes universitários, de sujeitos professores e alunos de IES públicas e particulares

\begin{tabular}{|c|c|c|c|c|c|}
\hline \multirow{2}{*}{ Itens } & \multicolumn{2}{|c|}{$\begin{array}{c}\text { Alunos } \\
(\mathrm{N}=463)\end{array}$} & \multicolumn{2}{|c|}{$\begin{array}{l}\text { Professores } \\
(\mathbf{N}=73)\end{array}$} & \multirow{2}{*}{$\mathbf{t}$} \\
\hline & Médias & $\begin{array}{l}\text { Desvios- } \\
\text {-padrão }\end{array}$ & Médias & $\begin{array}{l}\text { Desvios- } \\
\text {-padrão }\end{array}$ & \\
\hline $\begin{array}{l}\text { 1. Presença nas aulas, apenas nos } \\
\text { momentos próximos à chamada; }\end{array}$ & 45,04 & 29,77 & 37,99 & 26,76 & $2,06^{*}$ \\
\hline $\begin{array}{l}\text { 2. Presença apenas nas aulas } \\
\text { em que os professores fazem } \\
\text { chamada; }\end{array}$ & 42,97 & 29,84 & 37,73 & 28,68 & 1,44 \\
\hline $\begin{array}{l}\text { 3. Responder chamada em nome } \\
\text { de outros colegas faltosos; }\end{array}$ & 15,48 & 21,22 & 9,84 & 12,12 & $3,27 * *$ \\
\hline $\begin{array}{l}\text { 4. Fotocopiar cadernos, resumos } \\
\text { e anotações elaborados pelos } \\
\text { colegas; }\end{array}$ & 48,23 & 30,51 & 42,89 & 26,51 & 1,56 \\
\hline $\begin{array}{l}\text { 5. Realização de outras atividades } \\
\text { alheias ao assunto da disciplina, } \\
\text { durante as aulas; }\end{array}$ & 41,15 & 26,38 & 29,47 & 19,83 & $4,45^{* *}$ \\
\hline $\begin{array}{l}\text { 6. Adoção de estratégias de divi- } \\
\text { são dos trabalhos em grupo nas } \\
\text { diversas disciplinas; }\end{array}$ & 43,60 & 29,91 & 43,34 & 27,15 & 0,07 \\
\hline $\begin{array}{l}\text { 7. Cópia de trabalhos prontos } \\
\text { da internet para entregar aos } \\
\text { professores; }\end{array}$ & 36,86 & 28,82 & 39,21 & 24,66 & 0,73 \\
\hline $\begin{array}{l}\text { 8. Solicitação, ou pagamento a } \\
\text { outras pessoas para fazer os tra- } \\
\text { balhos escolares solicitados pelos } \\
\text { professores; }\end{array}$ & 24,73 & 23,25 & 30,15 & 21,49 & $-1,98^{*}$ \\
\hline $\begin{array}{l}\text { 9. Colar na prova em pelo menos } \\
\text { uma disciplina; }\end{array}$ & 52,13 & 33,24 & 46,58 & 25,94 & 1,63 \\
\hline $\begin{array}{l}\text { 10. Colar na prova em pelo me- } \\
\text { nos metade das disciplinas. }\end{array}$ & 42,27 & 30,64 & 33,62 & 22,11 & $2,92 * *$ \\
\hline Total & 392,68 & 196,94 & 350,79 & 164,69 & $1,96^{*}$ \\
\hline
\end{tabular}

$* \mathrm{p}<05$

$* * \mathrm{p}<01$ 


\section{TABELA 6}

Médias, desvios-padrão e teste das diferenças entre as médias dos escores indicativos da frequência de emissão de comportamentos de trapaça pelos professores universitários, de sujeitos professores e alunos de IES públicas e particulares

\begin{tabular}{|c|c|c|c|c|c|}
\hline \multirow{2}{*}{ Itens } & \multicolumn{2}{|c|}{$\begin{array}{l}\text { Alunos } \\
(\mathrm{N}=463)\end{array}$} & \multicolumn{2}{|c|}{$\begin{array}{l}\text { Professores } \\
(\mathrm{N}=73)\end{array}$} & \multirow{2}{*}{$\mathbf{t}$} \\
\hline & Médias & $\begin{array}{l}\text { Desvios- } \\
\text {-padrão }\end{array}$ & Médias & $\begin{array}{l}\text { Desvios- } \\
\text {-padrão }\end{array}$ & \\
\hline $\begin{array}{l}\text { 1. Chegam dez minutos depois } \\
\text { da hora prevista para o início da } \\
\text { aula }\end{array}$ & 30,53 & 30,90 & 32,62 & 27,80 & $-0,58$ \\
\hline $\begin{array}{l}\text { 2. Terminam a aula dez minutos } \\
\text { mais cedo }\end{array}$ & 41,40 & 32,92 & 40,47 & 28,98 & 0,25 \\
\hline 3. Dão aulas "sem conteúdos" & 27,85 & 27,11 & 21,23 & 21,99 & $2,31 *$ \\
\hline $\begin{array}{l}\text { 4. Lêem ou pedem aos alunos } \\
\text { que façam a leitura, em sala de } \\
\text { aula, dos textos }\end{array}$ & 26,22 & 26,58 & 26,53 & 24,50 & $-0,10$ \\
\hline $\begin{array}{l}\text { 5. Preenchem grande parte da } \\
\text { aula com narrativas de casos } \\
\text { pessoais }\end{array}$ & 17,78 & 21,49 & 17,70 & 16,35 & 0,04 \\
\hline $\begin{array}{l}\text { 6. Definem o conteúdo do pro- } \\
\text { grama da disciplina em função da } \\
\text { opinião dos alunos }\end{array}$ & 19,97 & 22,62 & 21,88 & 19,03 & $-0,77$ \\
\hline $\begin{array}{l}\text { 7. Solicitam aos alunos que } \\
\text { façam seminários em substituição } \\
\text { às aulas }\end{array}$ & 34,05 & 29,74 & 34,47 & 24,15 & $-0,30$ \\
\hline $\begin{array}{l}\text { 8. Favorecem, na nota, os alunos } \\
\text { mais próximos. }\end{array}$ & 19,32 & 25,72 & 17,12 & 20,42 & 0,82 \\
\hline 9. Aplicam provas em duplas & 13,83 & 18,74 & 26,07 & 21,18 & $-5,09 * *$ \\
\hline $\begin{array}{l}\text { 10. Utilizam auto-avaliação dos } \\
\text { alunos como critério para atribui- } \\
\text { ção de notas }\end{array}$ & 14,24 & 21,21 & 13,92 & 17,68 & 0,14 \\
\hline $\begin{array}{l}\text { 11. Dão provas compensatórias } \\
\text { aos alunos que foram mal na } \\
\text { prova }\end{array}$ & 14,41 & 19,90 & 24,67 & 24,60 & $-3,96 * *$ \\
\hline $\begin{array}{l}\text { 12. Atribuem notas pela partici- } \\
\text { pação dos alunos }\end{array}$ & 26,84 & 24,35 & 28,81 & 22,95 & $-0,68$ \\
\hline
\end{tabular}




\begin{tabular}{l|cc|cc|c|}
$\begin{array}{l}\text { 13. Avaliam com maior rigor os } \\
\text { alunos que apresentam melhor } \\
\text { desempenho }\end{array}$ & 24,80 & 27,81 & 25,99 & 25,26 & $-0,37$ \\
$\begin{array}{l}\text { 14. São menos rigorosos com } \\
\text { alunos que vão mal nas provas } \\
\begin{array}{l}\text { 15. Aplicam provas que os alunos } \\
\text { devem responder em casa }\end{array}\end{array}$ & 13,41 & 18,77 & 24,00 & 19,95 & $-4,41^{* *}$ \\
$\begin{array}{l}\text { 16. Informam anteriormente aos } \\
\text { alunos as questões de prova }\end{array}$ & 7,23 & 14,47 & 10,67 & 17,05 & $-1,84$ \\
$\begin{array}{l}\text { 17. Aplicam a mesma prova de } \\
\text { semestres anteriores }\end{array}$ & 19,92 & 24,50 & 24,64 & 22,51 & $-1,55$ \\
$\begin{array}{l}\text { 18. Definem o conteúdo da prova } \\
\text { em função da opinião dos alunos }\end{array}$ & 20,67 & 23,32 & 23,14 & 20,13 & $-0,85$ \\
\hline$\quad$ Total & 379,72 & 237,82 & 428,45 & 249,38 & $-1,59$ \\
\hline
\end{tabular}
** p $<01$

Ao comparar os escores obtidos por professores e estudantes de cursos superiores da EAF com aqueles obtidos pelos sujeitos das mesmas categorias de IES públicas e particulares, observaram-se diferenças estatisticamente significativas, em todos os comportamentos emitidos por alunos e professores, e nas somas desses, percebidos como muito menos frequentes na EAF, que adota regime acadêmico completamente diverso, com alguns casos de cursos em período integral, e mesmo em semiinternato.

Complementarmente, as médias dos escores do grupo dos professores coordenadores de cursos são significativamente mais baixas daquelas obtidas pelos professores ou alunos.

Por último, a análise das notas obtidas pelos 1.276 estudantes nas vinte disciplinas, nos dois bimestres, dos dois semestres distintos, indicou médias significativamente $(\mathrm{t}(\mathrm{gl}=1.274)=4.63 \mathrm{p}<001)$ diferentes, com os resultados do segundo bimestre sempre superiores àqueles do primeiro bimestre. Uma outra amostra aleatória, de outras nove disciplinas em dois bimestres distintos, do primeiro e segundo, apresentou resultados absolutamente na mesma direção, com diferenças significativas $(\mathrm{t}=2.87$ $\mathrm{p}<01$ ) entre as médias, sendo os escores mais altos no segundo que no primeiro bimestre. 


\subsection{Discussão e conclusões}

Os dados expostos nesse estudo mostram, primeiramente, que as escalas utilizadas para identificar as percepções de alunos, professores e coordenadores de cursos de graduação em diversas IES, das porcentagens de presença em sua Instituição de comportamentos acadêmicos e pedagógicos ilícitos - emitidos por docentes e discentes -, apresentam indicadores de importantes qualidades métricas destes instrumentos, o que recomenda a utilização dos mesmos para a medida das variáveis consideradas. As escalas apresentam boa configuração fatorial, altos índices de confiabilidade e os escores, em seus diferentes itens, também apresentam altos e positivos coeficientes de correlação com os escores totais na escala a que pertencem.

As respostas dos sujeitos demonstram que muitos dos comportamentos acadêmicos ilícitos são percebidos como praticados por uma enorme massa de estudantes, a maior parte deles com porcentagens superiores a $40 \%$. Índices alarmantes também estão presentes ao se considerar as condutas pedagógicas ilícitas emitidas pelos docentes, podendo-se observar que mais da metade dos comportamentos considerados, são percebidos como sendo emitidos por mais de $20 \%$ dos professores, de IES públicas e particulares. É importante ressaltar que os comportamentos ilícitos, emitidos por professores e estudantes, são percebidos como estando presentes tanto nas IES públicas como nas particulares, mais frequentes ainda nas IES públicas, naqueles aspectos relativos à topologia das aulas. Diferenças significativas, entretanto, só estão presentes em cinco dos onze comportamentos envolvendo a avaliação da aprendizagem, ainda que em todos os casos as frequências de condutas ilícitas por parte dos docentes sejam percebidas com maior ênfase nas IES públicas.

$\mathrm{Na}$ mesma direção, aparecem as diferenças entre as médias das notas atribuídas pelos docentes a seus alunos nos primeiros e segundos bimestres, com escores significativamente mais altos na segunda avaliação. Seria este também um indicador, agora mais objetivo, de condutas ilícitas dos docentes, procurando no segundo bimestre atribuir notas mais altas a seus alunos para elevar os índices de aprovação em suas disciplinas, evitando os dissabores que acompanham a reprovação dos estudantes? 
Estes dados indicam, com muita lucidez, a presença de comportamentos envolvendo trapaça no meio universitário brasileiro, do mesmo modo que identificaram Levitt e Dubner (2005) em escolas médias dos Estados Unidos da América.

Não há dúvidas, conforme as considerações de Masetto (2003), que tais condutas ilícitas emitidas por docentes e discentes comprometem a finalidade, os procedimentos pedagógico-acadêmicos para a aprendizagem, bem como os objetivos últimos da educação, facilitando o aparecimento do que Adorno (1996) denominou de semiformação. Ao mesmo tempo, estas condutas terminam por contaminar, conforme Habermas (1983), o próprio desenvolvimento das ações humanas e da cultura organizacional da IES e, por extensão, toda a sociedade, uma vez que esta poderá ser a grande vítima das consequências nefastas de uma formação deficitária no seio da universidade. Afinal, quais perfis de cidadãos estão sendo formados por estas instituições, se condutas desta natureza são emitidas ou permitidas no interior das IES? O que esse estudo procurou mostrar é que, independentemente da orientação pedagógica adotada, as trapaças percebidas não são capazes de resistir à menor apreciação crítica do teor nefasto que tais condutas representam para a formação cultural da sociedade.

Não se trata aqui de argumentar que um ou outro comportamento dos docentes em sala de aula poderiam ser entendidos como alternativas válidas ao processo educativo, como a utilização de seminários. O que de fato se está identificando neste estudo é a adoção de uma série de condutas por parte dos docentes e discentes que são rotuladas como ilícitas, trapaças, porque são emitidas com o intuído de buscar o menor esforço, de tirar proveito escuso, de manipular, de facilitar as consequências para uns e outros.

Mas por que há tanta trapaça no meio universitário, tanto por parte de professores, alunos e dirigentes? Por que poucos deixam de emitir condutas dessa natureza, ou não se mobilizam para denunciar, combater ou se diferenciar deste estado de coisas? A resposta pode ser buscada na existência de uma cultura no meio universitário que tudo compreende, tudo permite, tudo aceita, tudo pode ser validado. Infelizmente, nos dias atuais, poucas são as ilhas de excelência no meio acadêmico que primam por entender a educação superior como uma atividade, uma oportunidade para formar excelentes profissionais, de incrementar o conhecimento científico 
nas diversas áreas, de contribuir para o aprimoramento da sociedade, criando um ambiente favorável à educação, um padrão de excelência diferente do que se pode observar na sociedade como um todo.

Almeida (2007), em uma pesquisa de levantamento junto a 2.363 sujeitos de todas as partes do território nacional, mostrou que os sujeitos com nível superior de escolaridade apresentam esquemas cognitivos sobre diversos temas da atualidade completamente diferentes daqueles que só completaram o ensino médio. O que seria possível fazer com a população universitária brasileira se a educação superior tivesse altos níveis de qualidade, livre de condutas nefastas como estas identificadas e mensuradas nesse trabalho?

Seria desejável que novos estudos fossem conduzidos em outros ambientes, por outros pesquisadores, envolvendo outras variáveis, outras classes e, ainda, a cultura organizacional das IES que permite a existência de condutas acadêmico-pedagógicas ilícitas. No caso específico da cultura organizacional seria interessante analisar com maior objetividade a incidência de trapaças em práticas adotadas pela IES, como: aceitar matrículas fora do prazo, não imprimir diários nas primeiras semanas de aula, oferecer "cursos" de preparação para os alunos que irão se submeter aos exames nacionais de avaliação do Ministério da Educação, determinar que parte das notas dos alunos sejam atribuídas aos trabalhos e não às provas, entre outras. Este empreendimento acadêmico, a ser instituído por outras pesquisas, não teria outro sentido, a não ser o desejo de que novas luzes ajudem a elucidar este preocupante estado da educação superior brasileira. Talvez seja a hora de tratar cientificamente a educação, investigando criteriosamente o paradigma educacional que tem norteado a cultura das IES, a fim de propor objetivamente uma verdadeira revolução, no sentido atribuído por Kuhn (2000).

\section{Referências}

ADORNO, T. W. Teoria da Semicultura, Revista Educação e Sociedade, Campinas, ano XVII, n. 56, p. 388-411, Dez. 1996. 
Educação e Emancipação. Tradução de Wolfgang Leo Maar. Rio de Janeiro: Paz e Terra, 1995.

. Theorie der Halbbildung. Gesammelte Schriften, Herausgegeben von Rolf Tiedemann, v. 8, Vierte Auflage 1966, Frankfurt; Suhhrkamp Verlang, am Main 1972 (Sociologische Schriften I), p. 93-121.

ADORNO, T. W.; HORKHEIMER, Max. Dialética do Esclarecimento. Tradução de Guido Antônio de Almeida. Rio de Janeiro: JZE, 1985.

ALMEIDA, A. C. A cabeça do brasileiro. Rio de Janeiro: Record, 2007.

GOMES, L. R. Educação e Consenso em Habermas. Campinas: Alínea, 2007.

. A Indústria Cultural Hoje: o agir comunicativo como possibilidade de uma teoria crítica da educação. In: SEMINÁRIO INTERNACIONAL: A INDÚSTRIA CULTURAL HOJE, 2006, Piracicaba. Anais... Piracicaba: Universidade Metodista de Piracicaba, 2006. p. 473-485.

FOLHA. 30.000 professores faltam por dia em São Paulo. Jornal Folha de São Paulo, São Paulo, 11 Nov. 2007. Caderno Cidades, p. C 1.

HABERMAS, J. Moralbewusstsein und Kommunikatives Handeln. Suhrkamp Verlang: Frankfurt am Main, 1983.

. Teoría de la acción comunicativa. Madrid: Taurus, 1999.

- Teoría de la acción comunicativa: complementos y estudios previos. Tradução de Manuel Jiménez Redondo. Madrid: Catedra, 2001. HORKHEIMER, M. O Eclipse da Razão. Tradução de São Paulo: Centauro, 2000.

HOUAISS, Antônio. Dicionário Houaiss da Língua Portuguesa. Rio de Janeiro: Objetiva, 2004.

KUHN, T. S. A Estrutura das Revoluções Cientificas. Tradução de Beatriz Vianna Boeira e Nelson Boeira. São Paulo: Editora Perspectiva, 2000.

LEVITT, S.; DUBNER, S. Freaakonomics - o lado oculto e inesperado de tudo que nos afeta: as revelações de um economista original e politicamente incorreto. Tradução de Regina Lyra. Rio de Janeiro: Elsevier, 2005.

MASSETTO, M. T. Competência Pedagógica do Professor Universitário. São Paulo: Summus, 2003. 
MATTEI, Jean-François. A barbárie interior: ensaio sobre o i-mundo moderno. São Paulo: UNESP, 2002.

PLATÃO. A República. Tradução de Maria Helena da Rocha Pereira. Lisboa: Fundação Calouste Gulbenkian, 1993.

Data de registro: $27 / 11 / 2010$

Data de aceite: 18/05/2011 
